\title{
BRCA1/2 Mutations in Salivary Pleomorphic Adenoma and Carcinoma-ex-Pleomorphic Adenoma
}

\author{
Soussan Irani ${ }^{1}$, Farahnaz Bidari-Zerehpoush ${ }^{2}$
}

${ }^{1}$ Department of Oral Pathology, Dental Research Center, Dental Faculty, Hamadan and Griffith University, School of Medicine, Gold Coast, Australia, ${ }^{2}$ Department of Pathology, Loghman Hospital, Shahid Beheshti University of Medical Sciences, Tehran, Iran

Received : 16-05-17.

Accepted : 18-09-17.

Published : 30-11-17.

\section{INTRODUCTION}

Dleomorphic adenoma (PA) is the most common 1 benign salivary gland tumor, constituting $45 \%$ to $85 \%$ of all major and minor salivary gland tumours. ${ }^{[1,2]}$ It has been suggested that PA arises from myoepithelial cell and ductal cell differentiation into mesenchymal and epithelial structures. It is also believed that PA originates from reserve cells or stem cells of intercalated ducts which differentiate to mesenchymal and epithelial cells which may explain morphological diversity in PA, but the initiation factors of tumor progression are not fully understood. ${ }^{[3]}$ Carcinoma-ex-pleomorphic carcinoma (Ca-ex-PA), a high-grade malignancy, accounts for $5 \%-15 \%$ of all salivary cancers. ${ }^{[4]}$ Histologically, Ca-ex-PA contains both benign PA and

\begin{tabular}{|l|l|}
\hline \multicolumn{2}{c}{ Access this article online } \\
\hline Quick Response Code: & Website: www.jispcd.org \\
\hline
\end{tabular}

malignant component. ${ }^{[5]}$ The pathogenesis of Ca-ex-PA is not clear, but it is hypothesized that this tumor is malignant from the beginning or is a malignant transformation of a recurrent or a long-standing $\mathrm{PA}^{[6]}$ as longevity and recurrence appear to increase the risk of malignant transformation. Malignant changes are present in $1.3 \%-7.5 \%$ of PAs. ${ }^{[7]}$ The accumulation of genetic instabilities is suggested to be the main reason for malignant transformation in PA. ${ }^{[8]}$ Similar to the majority of tumors, PA is a multifactorial, polygenic disease. Salivary Ca-ex-PA develops from a PA due to loss of heterozygosity on $8 \mathrm{q}, 12 \mathrm{q}$, and $17 \mathrm{p} \cdot{ }^{[9]}$ It is

Address for correspondence: Dr. Soussan Irani, Shahid Fahmide Blvd, Dental Faculty, Hamadan, Iran. E-mail: sousanirani@gmail.com

This is an open access article distributed under the terms of the Creative Commons Attribution-NonCommercial-ShareAlike 3.0 License, which allows others to remix, tweak, and build upon the work non-commercially, as long as the author is credited and the new creations are licensed under the identical terms.

For reprints contact: reprints@medknow.com

How to cite this article: Irani S, Bidari-Zerehpoush F. BRCA1/2 mutations in salivary pleomorphic adenoma and carcinoma-ex-pleomorphic adenoma. J Int Soc Prevent Communit Dent 2017;7:S155-62. 
suggested that heredity may play a crucial role in its development. ${ }^{[10]}$

BRCA1/2 genes involve in some biological processes expressed in different cells. BRCA1 regulates all phases of the cell cycle and triggers the cell response to DNA damage which blocks cell proliferation and promotes apoptosis; therefore, it stops malignant transformation. In cases of mutation in BRCA1/2 genes, the accumulation of damaged DNA occurs in the replicating cells, resulting in cancer development. In $2 \%-3 \%$ of all breast cancers, BRCA $1 / 2$ mutations have been reported. ${ }^{[1]]}$ Altered expression level of BRCA1 is associated with poor prognosis and shortened survival in breast cancer. ${ }^{[12]}$ BRCA2 mutation is also associated with a high risk of prostate cancer and a worse prognosis. ${ }^{[13]}$ Salivary glands and breast tissue are composed of tubular acinar exocrine glands; therefore, it can be expected to share similar pathological disorders. There is enough evidence of developing the same types of tumors in both tissues. One of these neoplasms is PA which has been reported in both salivary glands and breasts. ${ }^{[14,15]}$ Therefore, there is a need for investigations on the mechanisms associated with tumorigenesis. Immunohistochemistry of BRCA $1 / 2$ proteins in tumor cells can be a useful method in patient screening. ${ }^{[16]}$

The aim of this study was to determine the prevalence of BRCA1/2 mutations in PA and CA-ex-PA which has beneficial prognostic factors for patients with examined salivary gland tumors.

\section{Materials and Methods}

\section{Patient Selection}

As Ca-ex-PA is not a common lesion, only 45 cases were found in the Archive of Pathology Department of Loghman Hakim Hospital, Tehran, Iran, from 2000 to 2016. Therefore, 45 cases of PA were selected to make better match between two tumor types. As the paraffin blocks of the patients were used for this study, the ethical committee of the university declared that there was no need for ethical approval.

\section{IMMUNOHISTOCHEMICAL ASSESSMENT}

First, the formalin-fixed, paraffin-embedded samples were cut for preparing $\mathrm{H}$ and $\mathrm{E}$ staining to confirm the diagnosis. Then, $5 \mu \mathrm{m}$ cut sections were deparaffinized, rehydrated, and immersed in $\mathrm{pH} 6.0$ citrate buffer. Heat-induced antigen retrieval was performed for $20 \mathrm{~min}$. Slides were incubated with primary mouse monoclonal anti-BRCA1 antibody (Abcam, ab16780) at 1:90 dilution and primary rabbit polyclonal anti-BRCA2 antibody (Abcam, ab 27976) at 1:80 for $1 \mathrm{~h}$ at room temperature, followed by incubation with secondary antibody for $30 \mathrm{~min}$ and immunostained with $\mathrm{DAB}$
(3, 3'-diaminobenzidine) for $5 \mathrm{~min}$ as a chromogen and hematoxylin as counterstain. Breast cancer tissue served as positive control.

\section{VARIABLE CONSIDERATIONS}

Brown cytoplasmic/nuclear staining was considered to be a positive immunoreactivity for BRCA1, and brown nuclear staining was considered a positive staining for BRCA2. All positive staining were evaluated using a semi-quantitative scoring system for the percentage of positively stained cancer cells as follows: occasional staining but $<10 \%$ were considered negative, $10 \%-40 \%$ were considered mild, $40 \%-70 \%$ were scored moderate, and $>70 \%$ were considered intense staining. ${ }^{[17]}$

\section{Statistical anAlyses}

Analyses were conducted through SPSS software version 22.0 (SPSS, Inc., Chicago, IL, USA). Chi-square test was used to examine the differences between the variables. Significant level was set at 0.05 . To employ Chi-square test, all the 45 cases of Ca-ex-PA were considered as one group (regardless of histological subtypes).

\section{RESULTS}

The studied population consisted of ninety samples (45 samples of each lesion; PA or Ca-ex-PA). Thirty samples of PA were female and 15 were male, with a mean age of 56.4 years (range: $23-80$ years). Of CA-ex-PA samples, 32 were female and 13 were male, with a mean age of 60.3 years (range: $31-79$ years). The parotid gland was the main site affected by PA in thirty cases, followed by minor salivary glands of palate in ten cases, and the remaining five cases affected by submandibular glands. Of the 45 cases of Ca-ex-PA, 38 cases involved the parotid glands, 6 cases palatal salivary glands, and only one case was found in submandibular glands. In general, 93.3\% of PA samples showed positive staining for BRCA1 (in myoepithelial cells); however, BRCA2 positivity was found in $60 \%$ of samples (in myoepithelial cells) [Figures 1-3]. Among the 45 samples of Ca-ex-PA, $93.3 \%$ of showed positivity for BRCA1 and $80 \%$ of samples showed positivity for BRCA2. Chi-square test found differences between PAs and Ca-ex-PAs regarding BRCA1/2 mutations in ductal cells and myoepithelial cells $(P=0.007,0.000)$, respectively. Mann-Whitney test showed that there was a significant difference between BRCA1 expression level in myoepithelial cells not in ductal cells in compared groups $(P=0.000)$. In addition, there were significant differences between BRCA2 expression levels in both ductal cells $(P=0.004)$ and myoepithelial cells $(P=0.000)$ in examined groups. 


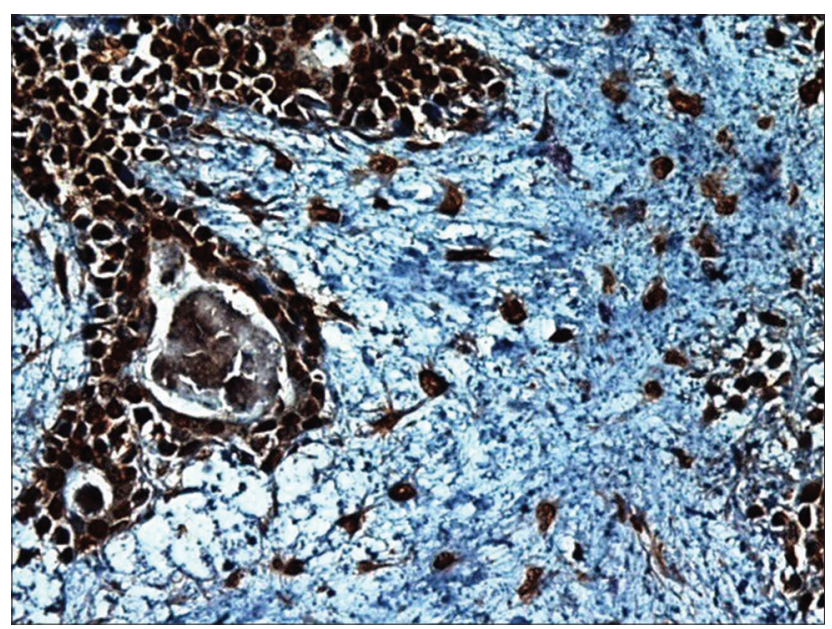

Figure 1: Higher magnification shows BRCA1 positivity in pleomorphic adenoma sample. Notice nuclear/cytoplasmic positivity in ductal cells, myoepithelial cells, and the cells in the myxoid material

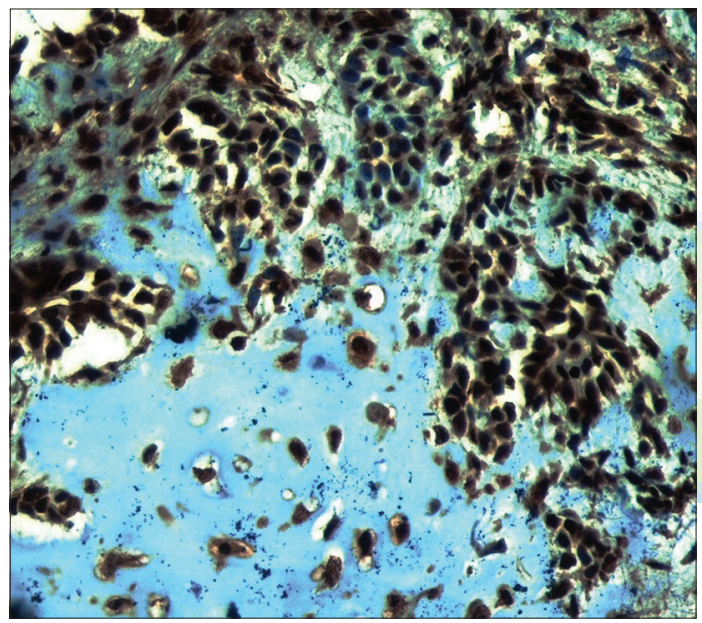

Figure 2: High power shows BRCA1 nuclear/cytoplasmic positivity in myoepithelial cells and the cells in the chondroid material in pleomorphic adenoma sample

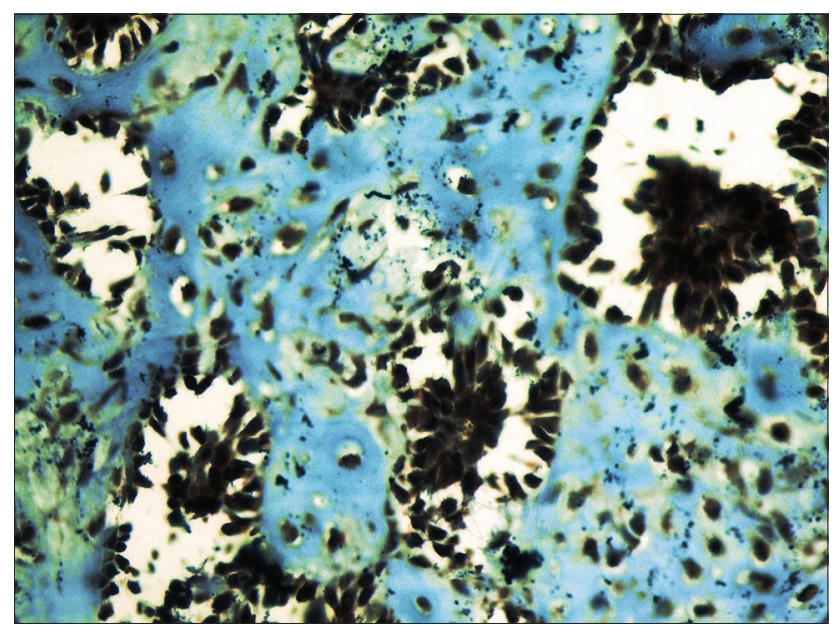

Figure 3: Higher magnification indicates BRCA2 nuclear positivity in myoepithelial cells and the cells in the chondroid material in pleomorphic adenoma samples
Among the 45 cases of Ca-ex-PA, there were 19 cases of adenocarcinoma not otherwise specified (AdNOS), 12 cases of salivary ductal carcinoma (SDC), 5 cases of epithelial-myoepithelial carcinoma (EMC), 5 cases of myoepithelial carcinoma (MC), 3 cases of adenoid cystic carcinoma (AdCC), and one case of polymorphous low-grade adenocarcinoma (PLGA). Tables 1 and 2 summarize BRCA1/2 staining in PA and Ca-ex-PA samples, respectively. All samples except two AdNOS samples and one SDC sample were positive for BRCA1 mutation in ductal cells [Figures 1-3]. In addition, all samples except four AdNOS samples, three SDC

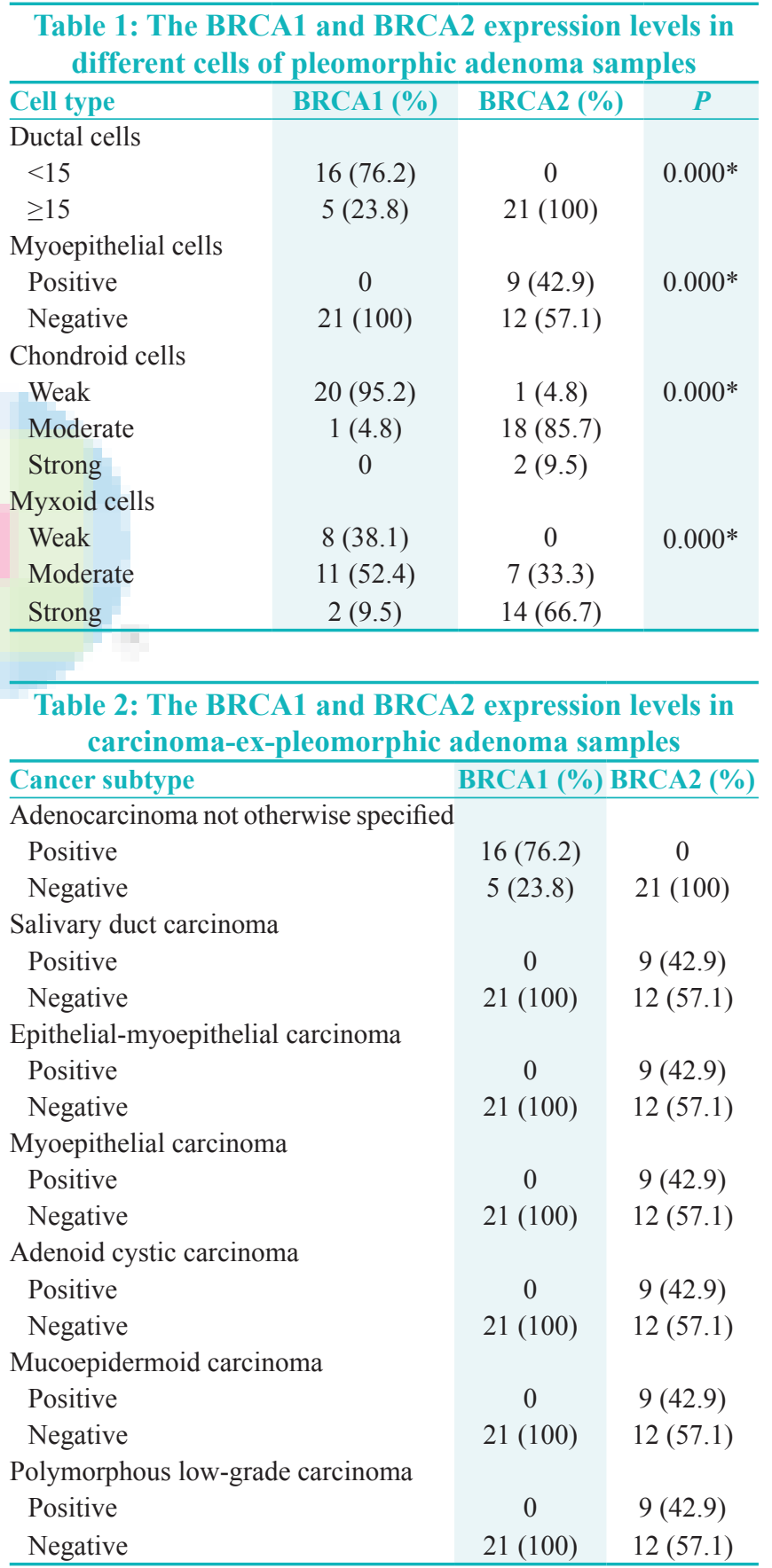


samples, and two MC samples were positive for BRCA2 mutation in ductal cells. Figures 4-15 show BRCA1/2 mutations in examined samples.

\section{DISCUSSION}

According to the morphological and immunohistochemical features, Ca-ex-PAs are classified into two groups. The first group constitutes those with ductal epithelial differentiation, probably derived from ductal luminal cells, including AdNOS, SDC, MEC, and PLGA. The second group comprises those with myoepithelial differentiation, likely derived from the precursor of myoepithelial and ductal cells, such as MC, EMC, and AdCC. ${ }^{[8]}$ Although both luminal and myoepithelial cells may undergo carcinomatous transformation, it is believed that, in most cases, malignancy arises from the luminal structures. ${ }^{[18]} \mathrm{Ca}$-ex-PA arises in a primary or recurrent PA mainly in the parotid gland. A low rate of recurrence and regional metastasis are the clinical features of Ca-ex-PAs. The malignant part of that is mostly a high-grade carcinoma such as SDC or MC. ${ }^{[19]}$

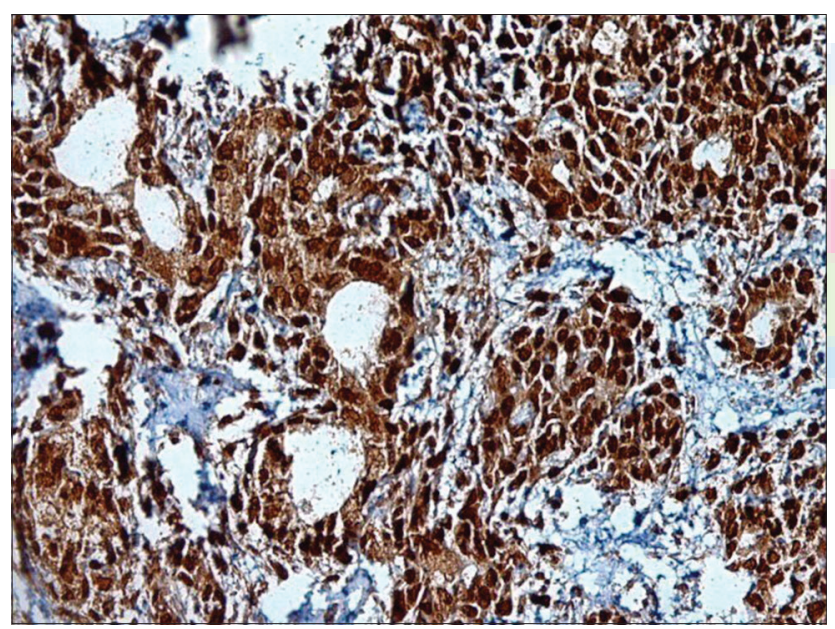

Figure 4: High-power photomicrograph exhibits a strong nuclear cytoplasmic BRCA1 positivity in adenocarcinoma not otherwise specified subtype. Note all ductal and myoepithelial cells show positivity

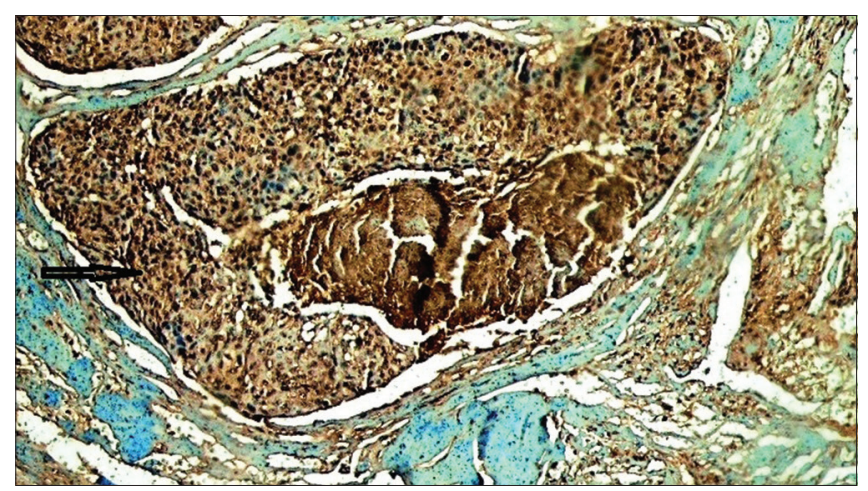

Figure 6: Lower magnification demonstrates a strong BRCA1 nuclear/ cytoplasmic positivity in salivary ductal carcinoma subtype. Arrow indicates the intraductal component
As there are similarities between the embryogenesis of salivary gland and breast as well as the dual epithelialmyoepithelial cell differentiation in both tissues, it is logical to expect the occurrence of salivary gland-type neoplasm in the breast. ${ }^{[14]}$ Some neoplasms of the breast have similar histological features to salivary gland tumors. In addition, the same genetic abnormalities are found in both salivary gland tumours and breast cancers. For example, a recurrent $t(6 ; 9)$ translocation resulting in the formation of the MYB-NFIB fusion gene can be found in AdCC of both salivary glands and breast. ${ }^{[20]}$ DNA repair deficiencies are described as risk factors in several cancers. Different proteins are involved in repairing the DNA damage. In case of inefficiency of one of these mechanisms, some others promote the DNA repair. ${ }^{[21]}$ BRCA1/2 genes involve in DNA repairing. ${ }^{[11]}$ To the best of our knowledge, this is the first time that BRCA1/2 mutations have been investigated in two salivary gland tumors. In general, the present

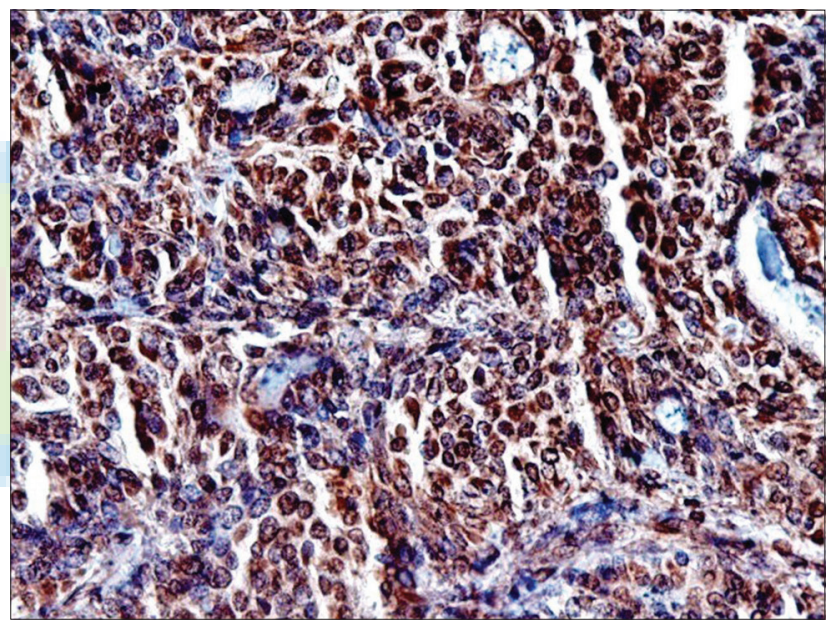

Figure 5: High-power photomicrograph indicates a strong nuclear BRCA2 positivity in adenocarcinoma not otherwise specified subtype. Positive staining is observed in majority of myoepithelial cells and ductal cells

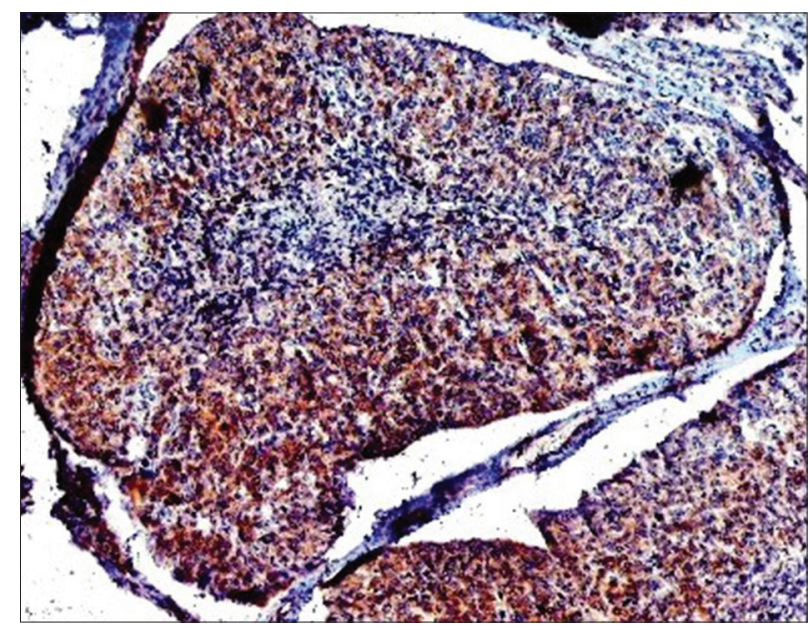

Figure 7: Low-power photomicrograph shows a strong BRCA2 nuclear positivity in salivary ductal carcinoma subtype 


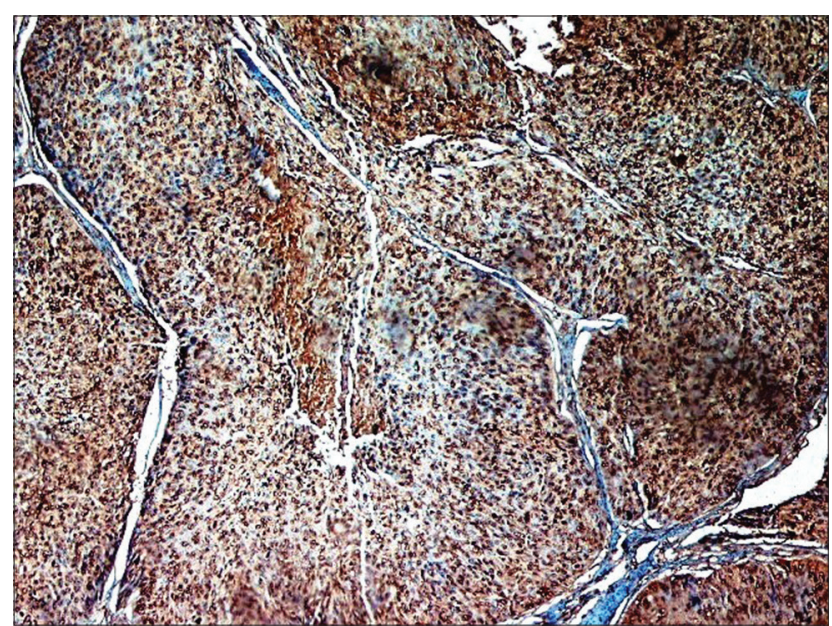

Figure

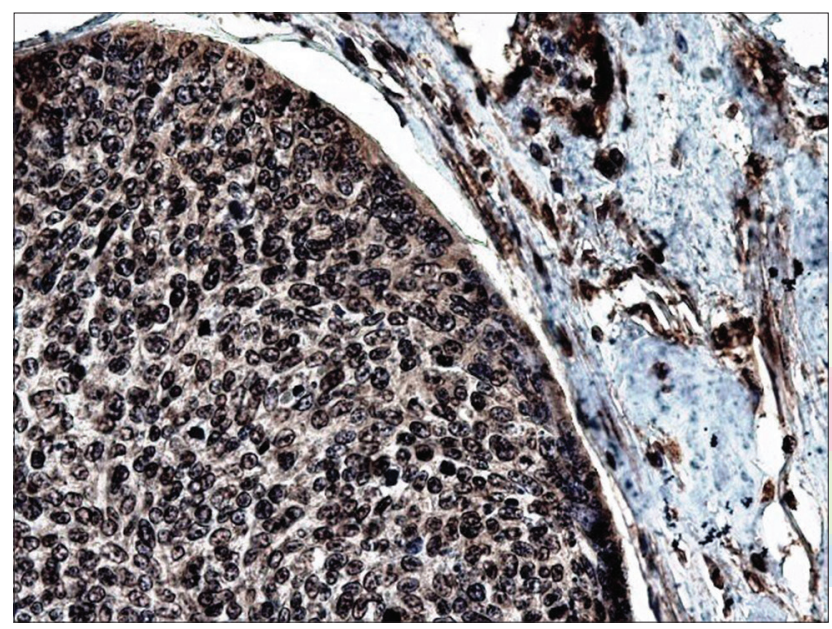

Figure 10: High magnification of strong BRCA1 positivity

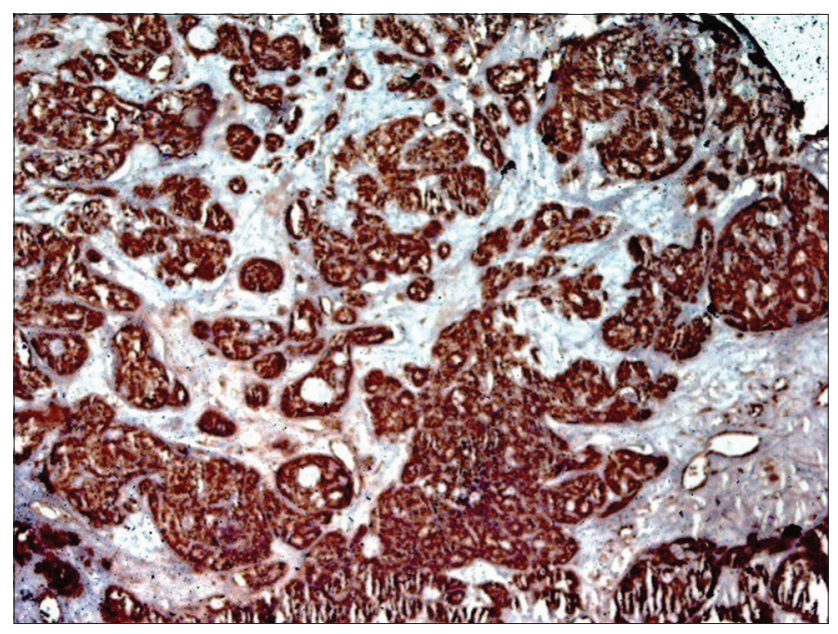

Figure 12: A lower power shows a strong nuclear/cytoplasmic BRCA

study indicated BRCA1 mutation in $95.6 \%$ of PAs and $60 \%$ of Ca-ex-PAs. Both luminal and myoepithelial

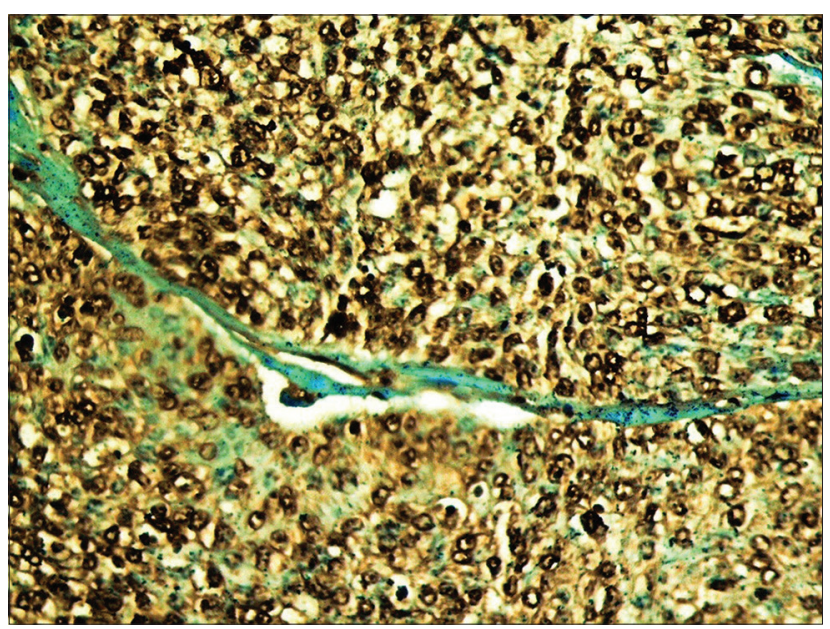

Figure 9: A higher power of BRCA2 positivity in epithelial-myoepithelia

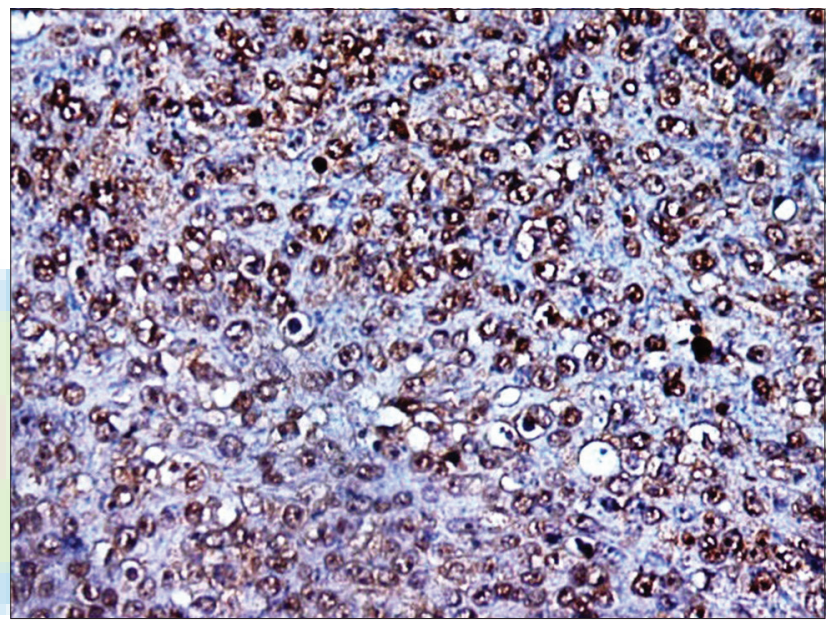

Figure 11: High-power photograph shows BRCA2 positivity

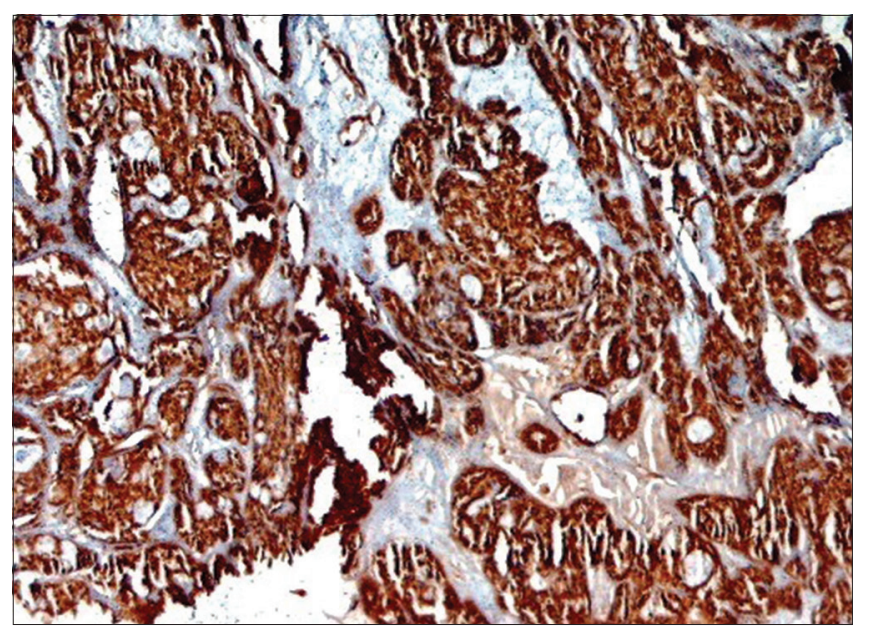

Figure 13:

cells showed BRCA1/2 mutations. Komenaka et al.

have found BRCA $1 / 2$ mutations in $60 \%-85 \%$ of breast 


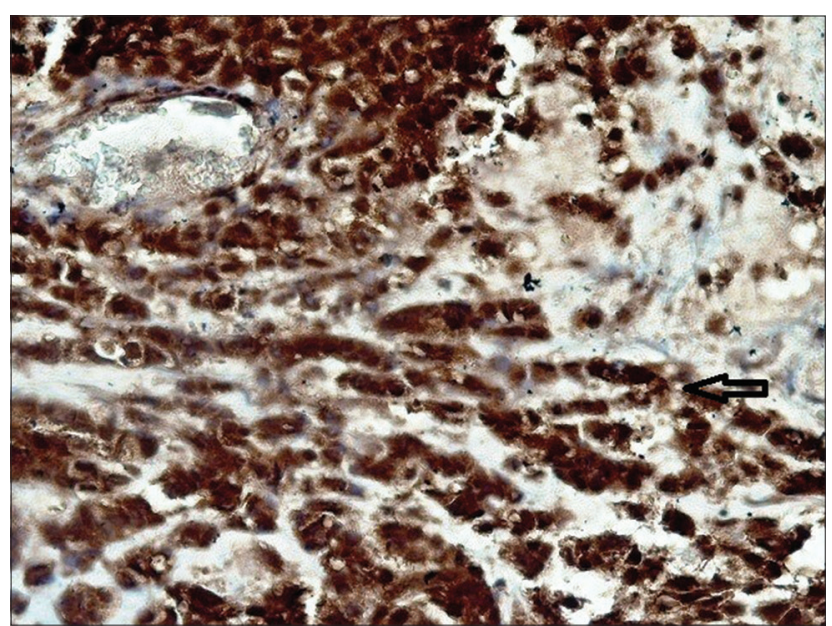

Figure 14: High magnification shows a strong BRCA1 positivity in polymorphous low-grade adenocarcinoma subtype. Note the single-cell pattern infiltration (arrow)

cancers. ${ }^{[12]}$ According to Madjd et al's. study, $46 \%$ of the breast cancer samples were BRCA1 positive. The authors arrived at the conclusion that BRCA1 protein can be a prognostic marker. ${ }^{[22]}$ Petrucelli et al. have shown BRCA $1 / 2$ mutations in $50 \%$ of all hereditary breast cancers. ${ }^{[23]}$ Strickland et al. in a study on high-grade serous ovarian cancer found $94.1 \%$ positivity of BRCA 1 in the samples. ${ }^{[24]}$ Lavie et al. have reported the BRCA1 germline mutation in $20 \%$ of uterine serous papillary carcinomas. ${ }^{[25]}$ These findings explain the importance of accurate identification of high-risk cases to increase life expectancy.

Several genomic alterations are associated with progression from PA to Ca-ex-PA including those in pleomorphic adenoma gene 1 (PLAG1), HMGA2, MDM2, TP53, MYC, and epidermal growth factor receptor. ${ }^{[26-28]}$ In addition, the amplification of MDM2, HMGA2, and deletion of 5q23.2q31.2 and 8q22.1q24.1 is an important factor in the transition from PA to Ca-ex-PA. ${ }^{[29]}$ Therefore, molecular subtyping of salivary neoplasms can help in targeted therapies. ${ }^{[30]}$ Chromosomal translocations involving the long arms of chromosomes 8 (8q12), 12 (12q15), and 6 (6p21) have been reported in PAs. ${ }^{[31]}$ Chromosomal translocations of $8 \mathrm{q} 12$ usually lead to the activation of the PLAG1;[26] however, rearrangement of the other two genetics results in high mobility group (HMG) protein genes, such as HMGI-C and HMGIY.[32] PLAG1 has a dual role, as oncogene and as tumor suppressor. It promotes cellular growth and also inhibits proliferation. In pleomorphic adenoma-like tumor of the breast, PLAG1, activated by the reciprocal chromosomal translocations involving $8 \mathrm{q} 12$, is also rearranged and overexpressed in salivary PA. The abnormal expression of PLAG1 may result in a deregulation of PLAG1 target genes involving salivary

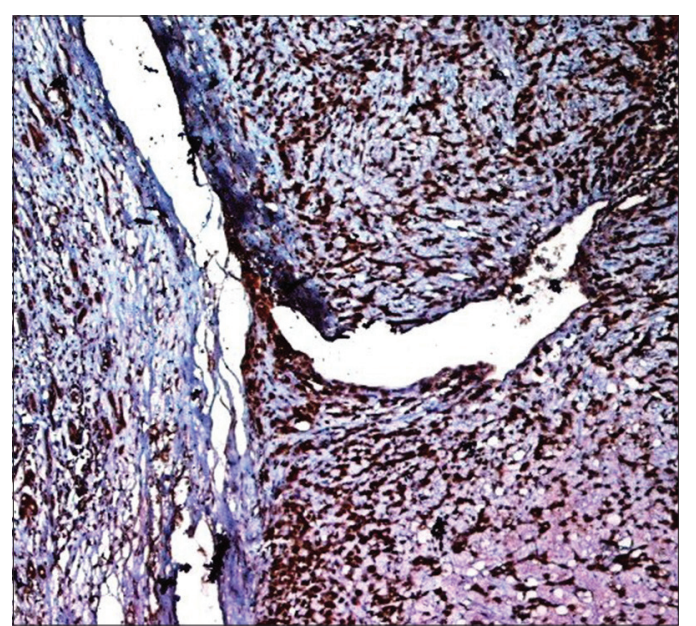

Figure 15: A lower magnification indicates a strong BRCA2 positivity in polymorphous low-grade adenocarcinoma subtype. Notice the single-file cells and infiltrative invasive front

gland tumorigenesis. ${ }^{[28]}$ PLAG1 overexpression has been detected in PA and in low-grade histopathologic subtypes of Ca-ex-PA, such as MC and EMC. ${ }^{[33]}$ In PA, PLAG1 expression has been demonstrated in both myoepithelial cells and ductal epithelial cells, supporting the hypothesis of a monoclonal origin of PA. Activation of PLAG1 during malignant transformation from PA to Ca-ex-PA is one of the pathways of malignant transformation. ${ }^{[34]}$ HMGA2 is a target gene in both PA and Ca-ex-PA. In PA, it is targeted with translocations involving 12q14-15. ${ }^{[27]}$ Bahrami et al. found PLAG1 abnormality and HMGA2 abnormality in $22.7 \%$ and $18.2 \%$ of Ca-ex-PA cases, respectively. However, only one case showed abnormality for both PLGA1 and HMGA2. ${ }^{[27]}$ Katabi et al. indicated that $67 \%$ of hypocellular myxoid PAs showed PLAG1 or HMGA2 rearrangements; however, only $29 \%$ of cellular PAs showed PLAG1 or HMGA2 rearrangements. The authors proposed that cellular PA might represent a discrete genetic subgroup. Besides, EWSR1 gene rearrangement has been shown as a common event in myoepithelial tumors such as salivary gland tumors. ${ }^{[35]}$

It is believed that p53 mutation is an early event in the progression of PA to Ca-ex-PA. In a previous report, p53 positivity was found in $0 \%-41 \%$ of PAs and $45.2 \%-75 \%$ of Ca-ex-PAs. ${ }^{[8]}$ However, another investigation carried out by DeRoche et al. indicated that $\mathrm{p} 53$ expression is not a reliable factor to predict early malignant transformation in PA. ${ }^{[8,36]}$ In addition, p53 and PIK3CA mutations have been identified in acinic cell carcinoma of the breast; nevertheless, the same mutations have not been detected in salivary gland acinic cell carcinoma. ${ }^{[20]}$ It has been suggested that BRCA1/2 and p53 pathways cooperate in breast cancer suppression. In addition, the p53 gene mutation has frequently been reported in breast cancer as 
well as other cancers. It is proposed that mutation in both pathways enhances tumor growth. ${ }^{[37]}$

Overexpression of HER-2/neu protein, a well-known proto-oncogene, was detected in the majority of SDCs of parotid gland associated with a poor prognosis. According to Skálová et al's. report, HER-2/neu protein was overexpressed in SDC and Ca-ex-PA but not in the benign cells of PA, suggesting the HER-2/neu protein as a useful tool in detecting malignant transformation of PAs. ${ }^{[38]}$

\section{Conclusions}

PA is the most common benign salivary gland tumor and Ca-ex-PA is a rare, aggressive salivary gland tumor with unknown pathogenesis. Some investigators believe that Ca-ex-PA is a carcinomatous transformation of PA; however, some others propose that it is a malignant tumor from the onset. This study was carried out to clarify the pathogenesis of Ca-ex-PA., The present study found a trend toward the presence of BRCA1/2 mutations in PA and Ca-ex-PA samples. As there are some similarities between salivary gland tissue and breast tissue, it may be logical to arrive at this conclusion that the patients with salivary gland neoplasms have a high risk of BRCA1/2 mutations. Previous studies have shown that the patients with BRCA1/2 mutation carriers are excellent cases for therapies, such as the poly (ADP) ribose polymerase inhibitor $^{[17]}$ IHC is a low-cost and efficient method; ${ }^{[39]}$ therefore, it can serve as a screening test for detection of BRCA1/2 dysfunction in salivary gland tumor. The knowledge of the spectrum of mutations can provide more efficient protocol for screening and therapeutic strategy. Rarity of Ca-ex-PA limits the number of cases. Further studies with more cases should be done to confirm the results of this study, especially those for rare subgroups.

\section{AcKnowledgment}

The authors would like to acknowledge the funding from Hamadan University of Medical Sciences.

\section{FINANCIAL SUPPORT AND SPONSORSHIP}

This work was supported by Hamadan University of Medical Sciences.

\section{CONFLICTS OF INTEREST}

There are no conflicts of interest.

\section{REFERENCES}

1. Irani S, Bidari-Zerehpoush F. How useful is the agnor staining method for the diagnosis of salivary gland tumors? Avicenna J Dent Res 2016;8:e25275.

2. Shishegar M, Ashraf MJ, Azarpira N, Khademi B, Hashemi B, Ashrafi A, et al. Salivary gland tumors in maxillofacial region: A retrospective study of 130 cases in a Southern Iranian population. Patholog Res Int 2011;2011:934350.

3. Chitturi RT, Veeravarmal V, Nirmal RM, Reddy BV.
Myoepithelial cells (MEC) of the salivary glands in health and tumours. J Clin Diagn Res 2015;9:ZE14-8.

4. Lim CM, Hobson C, Kim S, Johnson JT. Clinical outcome of patients with carcinoma ex pleomorphic adenoma of the parotid gland: A comparative study from a single tertiary center. Head Neck 2015;37:543-7.

5. Sakamoto Y, Fujita S, Adachi M, Sakamoto H, Naruse T, Yanamoto $\mathrm{S}$, et al. Carcinoma ex pleomorphic adenoma of the tongue: Difficulty in diagnosis between metastasis of breast cancer and salivary tumor. J Craniofac Surg 2017;28:e182-5.

6. Keerthi R, Raut RP, Vaibhav N, Ghosh A. Carcinoma ex pleomorphic adenoma: Diagnostic dilemma and treatment protocol. Indian J Dent 2014;5:157-60.

7. Mariano FV, Noronha AL, Gondak RO, Altemani AM, de Almeida OP, Kowalski LP, et al. Carcinoma ex pleomorphic adenoma in a Brazilian population: Clinico-pathological analysis of 38 cases. Int J Oral Maxillofac Surg 2013;42:685-92.

8. Kim JW, Kwon GY, Roh JL, Choi SH, Nam SY, Kim SY, et al. Carcinoma ex pleomorphic adenoma of the salivary glands: Distinct clinicopathologic features and immunoprofiles between subgroups according to cellular differentiation. J Korean Med Sci 2011;26:1277-85.

9. Antony J, Gopalan V, Smith RA, Lam AK. Carcinoma ex pleomorphic adenoma: A comprehensive review of clinical, pathological and molecular data. Head Neck Pathol 2012;6:1-9.

10. Nikolič N, Aničić" B, Tepavčević Z, Jezdić Z, Čarkić J, Toljić B, et al. Somatic mutation and polymorphism analysis in pleomorphic adenomas of the salivary glands. J Med Biochem 2013;32:4.

11. Cavanagh H, Rogers KM. The role of BRCA1 and BRCA2 mutations in prostate, pancreatic and stomach cancers. Hered Cancer Clin Pract 2015;13:16.

12. Komenaka IK, Ditkoff BA, Joseph KA, Russo D, Gorroochurn P, Ward M, et al. The Development of Interval Breast Malignancies in Patients with BRCA Mutations. Cancer .2004;100:2079-83.

13. Castro E, Goh C, Leongamornlert D, Saunders E, Tymrakiewicz M, Dadaev T, et al. Effect of BRCA mutations on metastatic relapse and cause-specific survival after radical treatment for localised prostate cancer. Eur Urol 2015;68:186-93.

14. Omar TA, ElDidi F, Nawar WM. A potential role for sex hormone receptor antagonists in treatment of malignant salivary gland tumours, as compared to breast cancer: A review of literature. Tanta Dent J 2013;10:75-85.

15. Piscuoglio S, Hodi Z, Katabi N, Guerini-Rocco E, Macedo GS, Ng CK, et al. Are acinic cell carcinomas of the breast and salivary glands distinct diseases? Histopathology 2015;67:529-37.

16. Vaz FH, Machado PM, Brandão RD, Laranjeira CT, Eugénio JS, Fernandes AH, et al. Familial breast/ovarian cancer and BRCA1/2 genetic screening: The role of immunohistochemistry as an additional method in the selection of patients. J Histochem Cytochem 2007;55:1105-13.

17. Andisheh-Tadbir A, Dehghani-Nazhvani A, Ashraf MJ, Khademi B, Mirhadi H, Torabi-Ardekani S, et al. MTA1 
expression in benign and malignant salivary gland tumors. Iran J Otorhinolaryngol 2016;28:51-9.

18. Altemani A, Martins MT, Freitas L, Soares F, Araújo NS, Araújo VC, et al. Carcinoma ex pleomorphic adenoma (CXPA): Immunoprofile of the cells involved in carcinomatous progression. Histopathology 2005;46:635-41.

19. Luers JC, Wittekindt C, Streppel M. Carcinoma ex pleomorphic adenoma of the parotid gland. Study and implications for diagnostics and therapy. Acta Oncol. 2009;48:132-136.

20. Piscuoglio S, Hodi Z, Katabi N, Guerini-Rocco E, Macedo GS, Ng CK, et al. Are acinic cell carcinomas of the breast and salivary glands distinct diseases? Histopathology 2015;67:529-37.

21. Aleskandarany M, Caracappa D, Nolan CC, Macmillan RD, Ellis IO, Rakha EA, et al. DNA damage response markers are differentially expressed in BRCA-mutated breast cancers. Breast Cancer Res Treat 2015;150:81-90.

22. Madjd Z, Karimi A, Molanae S, Asadi-Lari M. BRCA1 protein expression level and CD44(+) Phenotype in breast cancer patients. Cell J 2011;13:155-62.

23. Petrucelli N, Daly MB, Feldman GL. Hereditary breast and ovarian cancer due to mutations in BRCA1 and BRCA2. Genet Med 2010;12:245-59.

24. Strickland KC, Howitt BE, Shukla SA, Rodig S, Ritterhouse LL, Liu JF, et al. Association and prognostic significance of BRCA1/2-mutation status with neoantigen load, number of tumor-infiltrating lymphocytes and expression of PD-1/PD-L1 in high grade serous ovarian cancer. Oncotarget 2016;7:13587-98.

25. Lavie O, Hornreich G, Ben-Arie A, Rennert G, Cohen Y, Keidar R, et al. BRCA germline mutations in Jewish women with uterine serous papillary carcinoma. Gynecol Oncol 2004;92:521-4.

26. Matsuyama A, Hisaoka M, Nagao Y, Hashimoto H. Aberrant PLAG1 expression in pleomorphic adenomas of the salivary gland: A molecular genetic and immunohistochemical study. Virchows Arch 2011;458:583-92.

27. Bahrami A, Perez-Ordonez B, Dalton JD, Weinreb I. An analysis of PLAG1 and HMGA2 rearrangements in salivary duct carcinoma and examination of the role of precursor lesions. Histopathology 2013;63:250-62.

28. Ochal-Choińska AJ, Osuch-Wójcikiewicz E. Particular aspects in the cytogenetics and molecular biology of salivary gland tumours-Current review of reports. Contemp Oncol (Pozn) 2016;20:281-6.
29. Persson F, Andrén Y, Winnes M, Wedell B, Nordkvist A, Gudnadottir G, et al. High-resolution genomic profiling of adenomas and carcinomas of the salivary glands reveals amplification, rearrangement, and fusion of HMGA2. Genes Chromosomes Cancer 2009;48:69-82.

30. Andersson MK, Stenman G. The landscape of gene fusions and somatic mutations in salivary gland neoplasms - Implications for diagnosis and therapy. Oral Oncol 2016;57:63-9.

31. Pia-Foschini M, Reis-Filho JS, Eusebi V, Lakhani SR. Salivary gland-like tumours of the breast: Surgical and molecular pathology. J Clin Pathol 2003;56:497-506.

32. Geurts JM, Schoenmakers EF, Röijer E, Stenman G, Van de Ven WJ. Expression of reciprocal hybrid transcripts of HMGIC and FHIT in a pleomorphic adenoma of the parotid gland. Cancer Res 1997;57:13-7.

33. de Brito BS, Giovanelli N, Egal ES, Sánchez-Romero C, Nascimento JS, Martins AS, et al. Loss of expression of plag1 in malignant transformation from pleomorphic adenoma to carcinoma ex pleomorphic adenoma. Hum Pathol 2016;57:152-9.

34. Rotellini M, Palomba A, Baroni G, Franchi A. Diagnostic utility of PLAG1 immunohistochemical determination in salivary gland tumors. Appl Immunohistochem Mol Morphol 2014;22:390-4.

35. Katabi N, Ghossein R, Ho A, Dogan S, Zhang L, Sung YS, et al. Consistent PLAG1 and HMGA2 abnormalities distinguish carcinoma ex-pleomorphic adenoma from its de novo counterparts. Hum Pathol 2015;46:26-33.

36. DeRoche TC, Hoschar AP, Hunt JL. Immunohistochemical evaluation of androgen receptor, HER-2/neu, and p53 in benign pleomorphic adenomas. Arch Pathol Lab Med 2008;132:1907-11.

37. Minami A, Nakanishi A, Ogura Y, Kitagishi Y, Matsuda S. Connection between tumor suppressor BRCA1 and PTEN in damaged DNA repair. Front Oncol 2014;4:318.

38. Skálová A, Stárek I, Vanecek T, Kucerová V, Plank L, Szépe $\mathrm{P}$, et al. Expression of HER-2/neu gene and protein in salivary duct carcinomas of parotid gland as revealed by fluorescence in-situ hybridization and immunohistochemistry. Histopathology 2003;42:348-56.

39. Garg K, Levine DA, Olvera N, Dao F, Bisogna M, Secord AA, et al. BRCA1 immunohistochemistry in a molecularly characterized cohort of ovarian high-grade serous carcinomas. Am J Surg Pathol 2013;37:138-46. 